\title{
Surgical anatomy for Asian rhinoplasty
}

Taek Kyun Kim, Jae Yong Jeong

The PLUS Plastic Surgery Clinic, Seoul, Korea
Surgical anatomy is an important and fundamental aspect for all surgical procedures. Anatomy provides a surgeon with the basic and in-depth knowledge that is required and mandatory when performing an operation. Although this subject might be tedious and routine, it is compulsory and should not be overlooked or neglected to avoid any possible postoperative complications. An aggressive and hasty operation without anatomic considerations might cause adverse effects that are irreversible even though a surgical anatomy of the nose is quite simple.

Keywords: Musculoskeletal system / Nervous system / Nose / Rhinoplasty / Skin

\section{NASAL ENVELOPE: SKIN AND SOFT TISSUE ENVELOPE}

The nasal envelope, also known as skin and soft tissue envelope (SSTE), is the skin that covers the exterior of nose. The nasal envelope is made up of soft tissues and includes all intranasal soft tissue except the osteocartilaginous framework. Because the epidermis, dermis and subcutaneous tissues are among the tissues that make up the nasal envelope, it may at times lead to confusion for surgeons. No matter how thick or thin the skin may be, it is the SSTE which guides a surgeon for understanding the elasticity of the nasal envelope. Therefore, when performing rhinoplasty on a patient with thin skin, the skin and soft tissue might be considered as a single compound.

There are five layers that make up the nasal envelope. They include skin, superficial fatty layer, fibro-muscular layer, deep fatty layer, and perichondrium or periosteum (Figs. 1, 2) [1]. Asian nasal envelope is described as the skin with a thick subcutaneous fat layer which is oilier and denser in fibro-fatty layer. Thus, the elasticity of a patient's SSTE is an important aspect that must be considered during a surgical procedure. The thickness, texture and elasticity are significant characteristics of the

Correspondence: Taek Kyun Kim

The PLUS Plastic Surgery Clinic, 9 Dosan-daero 13-gil, Gangnam-gu, Seoul 06035, Korea

E-mail: psheroh2@naver.com

Received May 28, 2019 / Revised June 1, 2019 / Accepted June 3, 2019 nasal envelope and must be observed before any rhinoplasty procedure [2].

\section{Skin}

A nasal skin is very specialized organ keeping its own shape and characteristics with differing from other parts of body. In short, it especially at thick nasal tip keeps its own shape and pattern if cadaveric nasal skin is harvested and observed. It is an evidence of difficulty for change at nasal tip with surgical manipulation [3]. Therefore, it is important to evaluate individual characteristics of patient's skin before the operation to make surgical plan and predict prognosis because manipulation on cartilage framework is not visible due to thick skin during tip plasty [4].

The characteristics of the nasal envelope varies significantly in different portion of the nose. The nasal skin is thicker when the elasticity and stretch capacity are lower, and the proportions of the fibrous tissue and sebaceous glands are higher $[5,6]$. The nasal skin of dorsum is the thinnest, less sebaceous, and more mobile, hence can be shortened and wrinkled by a facial expression. However, it gets thicker caudally and is the thickest at supra-tip area. The dermal component of the skin is thinnest over the rhinion and thickest in the supratip area. The subcutaneous layer at the alar groove is very dense, hard and tightly attached to underlying tissue. An alar skin is considerably firm with tightly wrapping fibrous tissue. On the other hand, the 

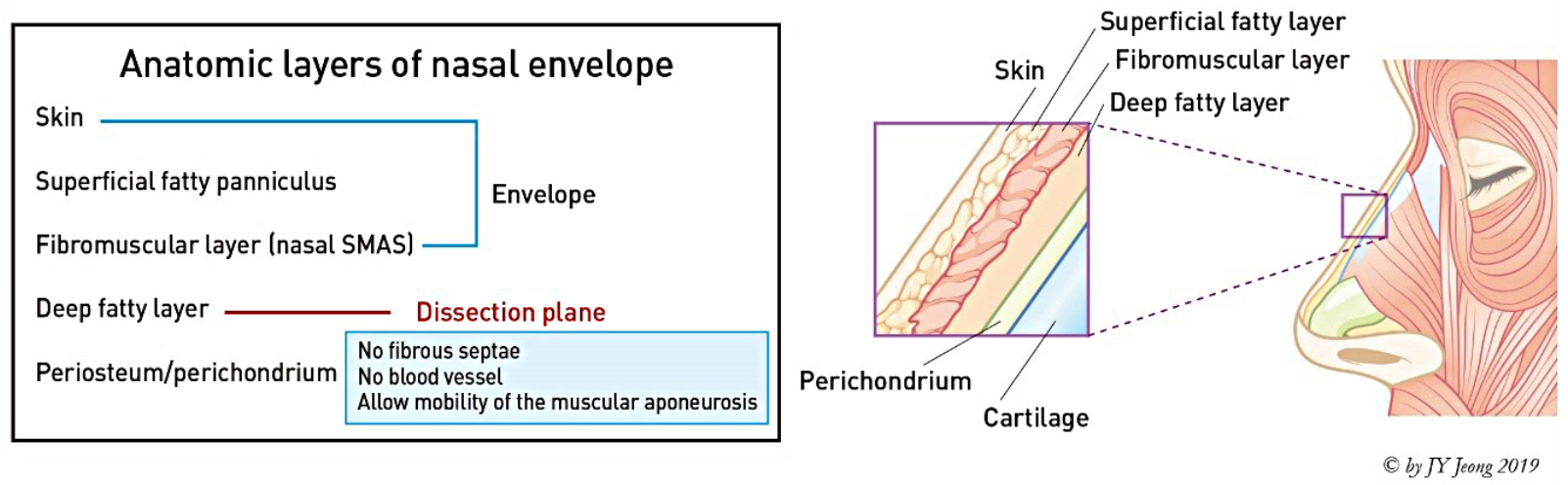

Fig. 1. Skin and soft tissue envelope, composition of the external nasal coverage (5 layers). SMAS, superficial musculo-aponeurotic system. Reprinted from Jeong JY [1].

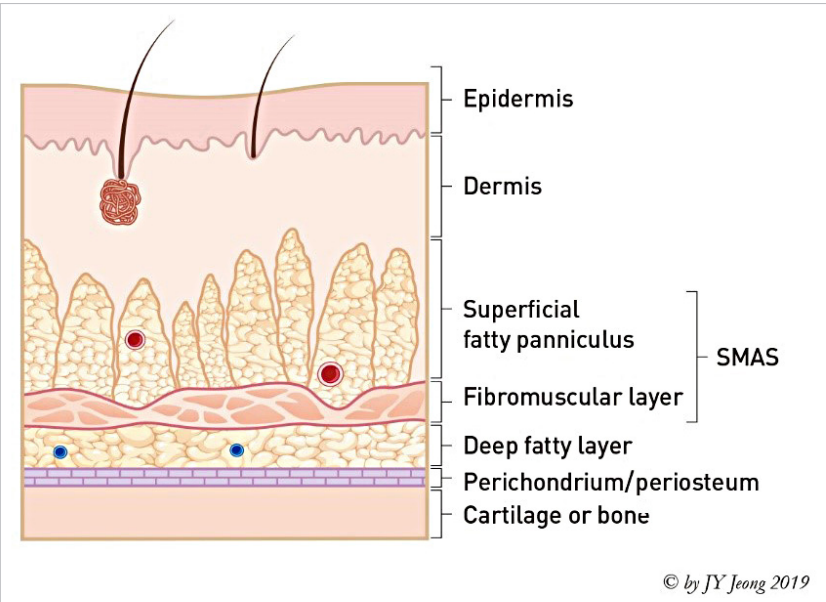

Fig. 2. Histologic layers of the nose. SMAS, superficial musculoaponeurotic system. Reprinted from Jeong JY [1].

columellar skin gets thinner and less sebaceous. The external part of columellar skin is tightly attached to medial crura and connected with vestibular skin internally (Table 1, Fig. 3) [7-10].

\section{Superficial fatty layer}

The superficial fatty layer consists of adipose tissue. In histology, the superficial fatty layer has interlacing vertical fibrous septae that is evenly distributed around the nose, typically at the glabella and the supratip area (Fig. 4). The superficial layer is tightly attached to the overlying skin with vertically oriented fibrous septae and supplied by horizontally running subdermal vascular network. It is thickest at the nasal radix and thinnest at the rhinion. The fat pad of the nasal radix is located over the procerus and extends to laterally medial brow and depressor supercilii. Fat pad of the supratip and sidewall is densely attached to dermis. The interdomal fat pad is located caudally from supratip fat and between both medial and middle crus. Dermocartilaginous ligament and interdomal ligament exist inferiorly (Fig. 5) [11,12].
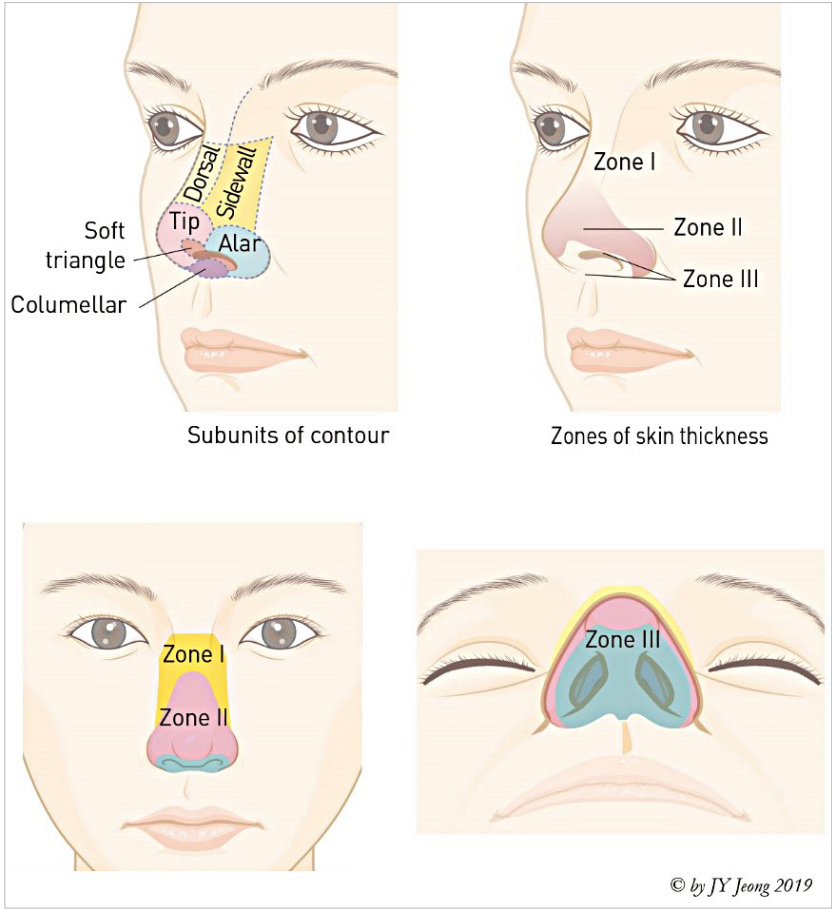

Fig. 3. The subunits of the nose and the difference in skin thickness by subunits. Zone II is the thickest portion [9]. Reprinted from Jeong JY [1].

\section{Fibromuscular layer}

The fibromuscular layer is the core part of nose; consisting of nasal superficial musculo-aponeurotic system (SMAS) along with a superficial fatty layer. The main function of the fibromuscular layer is to allow movement of the nasal envelope, to offer blood supply and to maintain the thickness of the skin. They also integrate and transmit the contractile force of nasal muscles [13]. The fibromuscular layer mainly consists of the procerus, anomalous nasi and transverse nasalis. It is also connected to the dermis layer tightly as a facial network, making facial animation possible [14]. Details about each muscle will be discussed later. Since nasal muscles originate from glabella 
Table 1. Zones of the nasal skin [10]

\begin{tabular}{|c|c|c|}
\hline Zone & Definition & Characteristics \\
\hline I & Covers the upper dorsum and sidewalls of the nose. & $\begin{array}{l}\text { Its skin is smooth, thin and nonsebaceous and glides easily over the underlying } \\
\text { bone and cartilage of the nasal hump. }\end{array}$ \\
\hline$\|$ & $\begin{array}{l}\text { Begins about } 1.5 \mathrm{~cm} \text { above the supratip area and covers most of the nasal tip } \\
\text { and alar lobules and to within } 4 \mathrm{~mm} \text { of the alar margin. }\end{array}$ & $\begin{array}{l}\text { Skin is stiff, thick, and filled with sebaceous glands, It is underlaing by a layer of } \\
\text { dense fat, which is } 6-10 \mathrm{~mm} \text { thick in the region of the supratip. }\end{array}$ \\
\hline |l| & $\begin{array}{l}\text { Includes a } 4 \mathrm{~mm} \text { strip along the alar margin, the soft triangles, the lower half of } \\
\text { the infratip lobule and the columella. }\end{array}$ & $\begin{array}{l}\text { Skin is smooth, thin, and nonsebaceous. There is little subcutaneous fat. Unlike } \\
\text { the smooth skin of zone I, the skin of zone III is fixed to the deep cartilage and } \\
\text { fibrofatty structures and dose not move easily. The medial and middle crura and } \\
\text { their intercrural groove are visible through the thin skin of zone III. }\end{array}$ \\
\hline
\end{tabular}

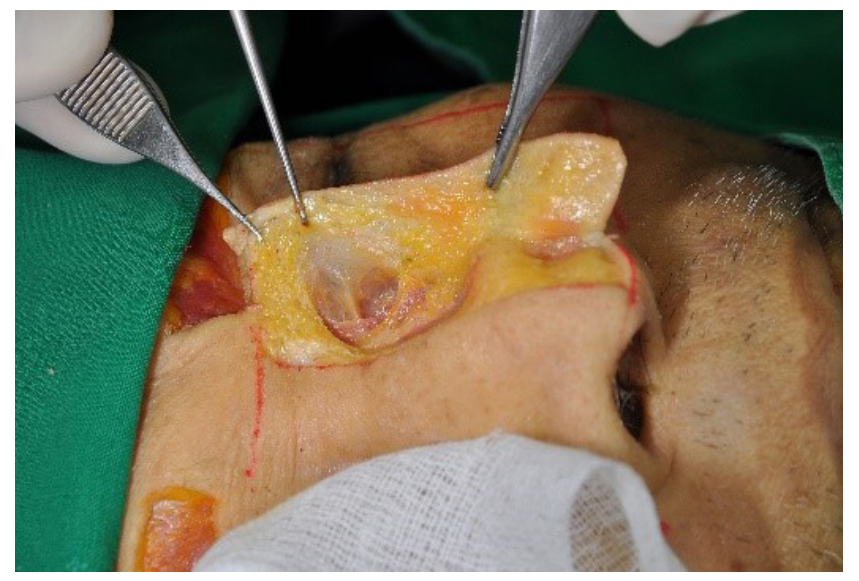

Fig. 4. The superficial layer is tightly attached to the overlying skin with vertically oriented fibrous septae.

Fig. 5. (A) Radix fat pad, supratip fat pad, sidewall fat pad and interdomal fat pad in front. (B) Radix fat pad, supratip fat pad, sidewall fat pad and interdomal fat pad in lateral. MCL, medial canthal ligament; LLSAN, levator labii superioris alaeque nasi muscle; TN, transverse nasalis muscle.
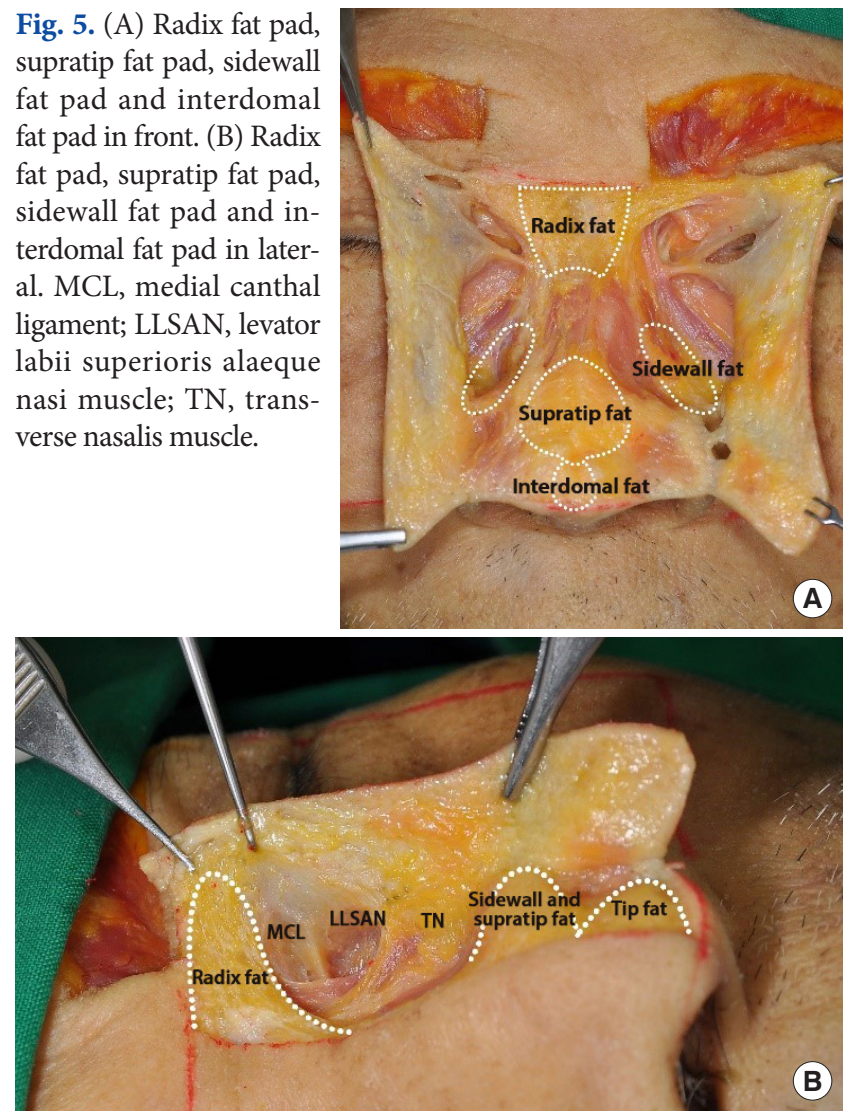

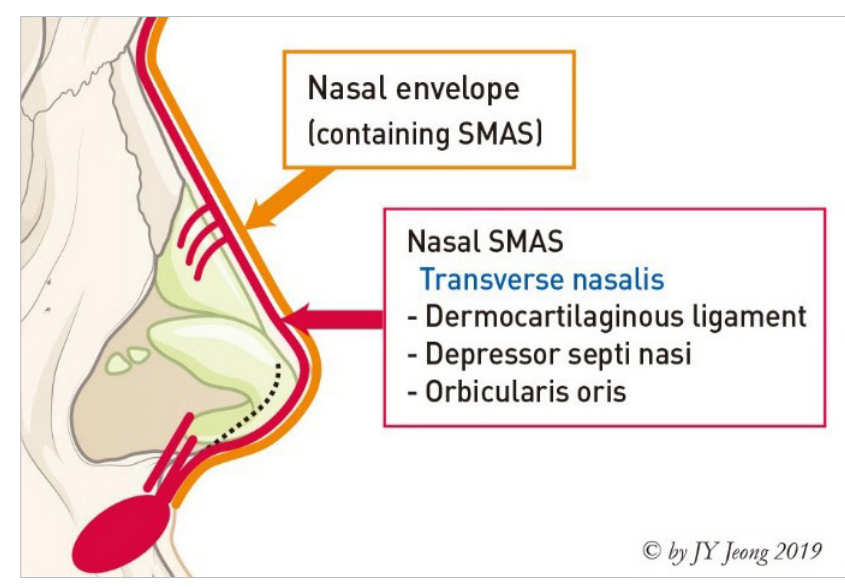

Fig. 6. As a single layer, nasal superficial musculo-aponeurotic system (SMAS) contains the various muscular system. Reprinted from Jeong JY [1].

and cheek, these muscles covering the underlying structure as a single unit, are fused in the middle (Fig. 6).

Although a nasal SMAS is considered as a continued structure from the facial SMAS, there is a slight compositional difference between the nasal dorsum and the tip. The proximal nasal SMAS is a collection of collagen supporting the dynamic property, whereas the distal nasal SMAS is a structure that is firmly attached between the skin and muscle (Fig. 7) [14]. According to Ghassemi et al. [13], SMAS can be divided into two types. Type $\mathrm{I}$ is the common architecture and can be found in the forehead, zygomatic and infraorbital regions. Characteristic of proximal portion of the nose composed of type I. Supratip and tip area consist of type II SMAS (Fig. 8). The characteristics of SMAS differ from each side above and below the scroll area (Fig. 9). While dissecting through open approach, the transitional zone where incorporation from the alar cartilage to upper lateral cartilage can be observed (Fig. 10) [15]. The dissection plane should be kept under deep fatty layer while monitoring the SMAS layer not to injure major vessels of the nose [16]. A severe injury on it may lead to a secondary contracture because the nasal SMAS is a core structure in blood supply. A damage to the nasal SMAS or deep dermis, accompanied by an uncontrolled postoperative inflammation might result in irre- 
versible complication related to formation of a severe and irregular scar at the nasal envelope (Fig. 11).

\section{Deep fatty layer}

The open approach is preferred to dissect the deep fatty layer while separating the nasal envelope. Lack of major vessels and fibrous septa along with the movement of muscular aponeurosis makes it less challenging. The advantage of dissection on this plane is possible to maintain the integrity of nasal envelope and to reduce the chance of damaging the neurovascular bundles.

\section{Periosteum or perichondrium (longitudinal fibrous sheath)}

The fifth layer consists of fused perichondrium or periosteum with fibrous tissue. It is located under the deep fatty layer. It can be divided as a periosteal component and a perichondral com-

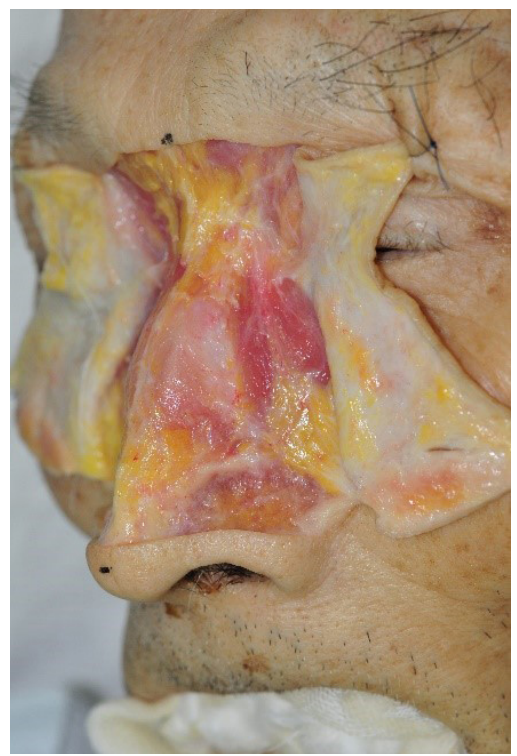

Fig. 7. Nasal superficial musculo-aponeurotic system. ponent. Histologically, a periosteum consists of superficial and deep layers [17]. These layers cover nasal bone, frontal process of maxilla and nasal portion of frontal bone. A perichondral component covers nasal cartilage and contains nutrient vessels. It wraps above and beneath the nasal cartilages, and fuses to form a hard, fibrous tissue at accessory cartilage (Fig. 12).

A periosteum is a special tissue consisting of fibro-vascular membrane. In Asian rhinoplasty, a dorsal implant material is usually located under the periosteum. It might cause migration, descent or deviation of the implant if pocket dissection is located within superficial plane, too wide or out of place. The periosteum becomes thicker as it ascends above the nasofrontal suture line. The collagen fibers called Sharpey's fiber, extending from the periosteum intervene with the suture line. Sharpey's fiber may hinder more subperiosteal cephalic dissection in cases with acute nasofrontal angle and flat nasal dorsum (Fig. 13) [18].

\section{NASAL BASE}

The nasal base is the least understood and thus most complex area of the nose. Therefore, analysis is also complex, and surgi-

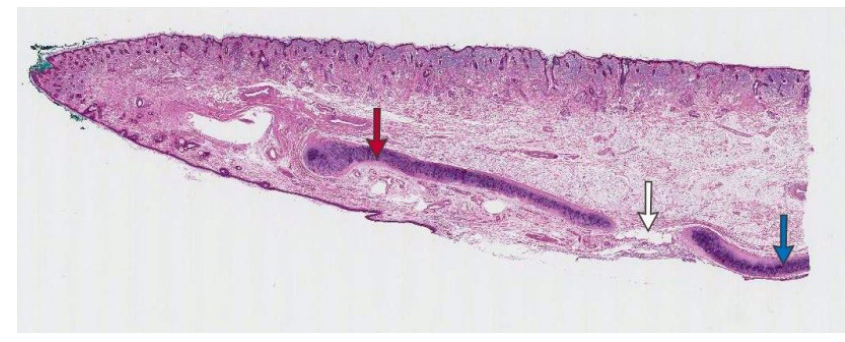

Fig. 9. The characteristics of superficial musculo-aponeurotic system are distinguished from each side of scroll area (H\&E stain, $\times 10$ ). Alar cartilage (red arrow), upper lateral cartilage (blue arrow), scroll area (white arrow).

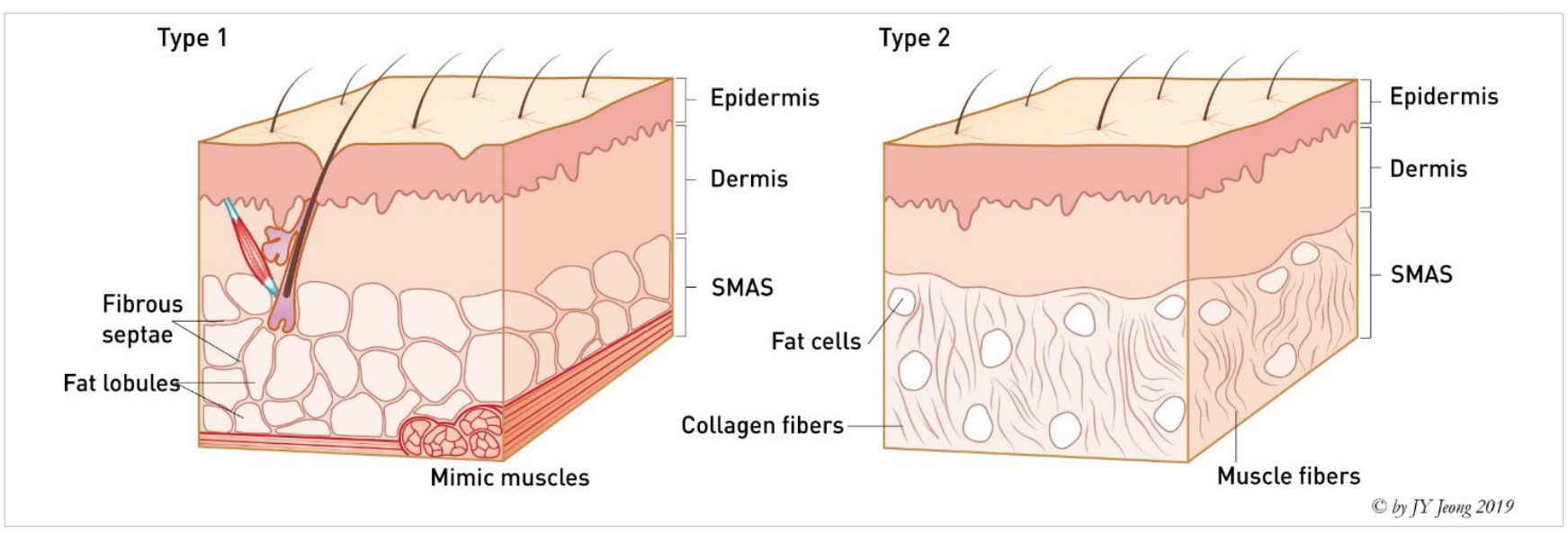

Fig. 8. Two models of superficial musculo-aponeurotic system (SMAS) architecture [13]. Reprinted from Jeong JY [1]. 

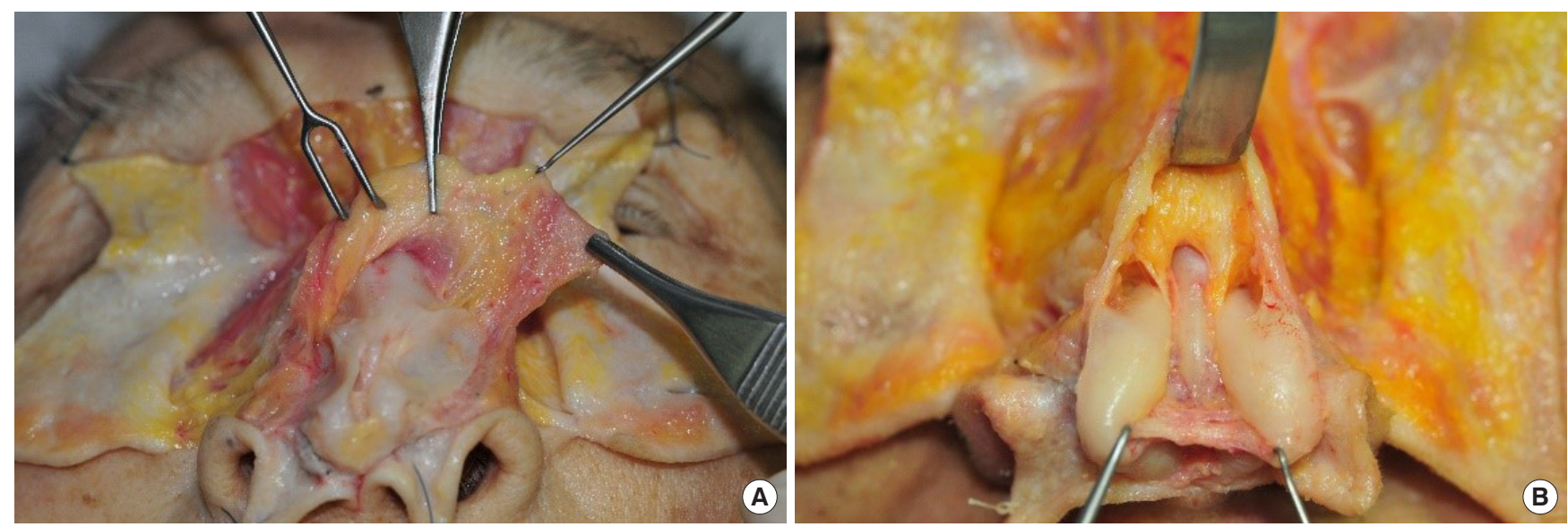

Fig. 10. Cadaveric model. (A) Nasal superficial musculo-aponeurotic system (SMAS) covering the transitional zone between alar cartilage and upper lateral cartilage. (B) Proximal nasal SMAS is partially connected to scroll area [15].
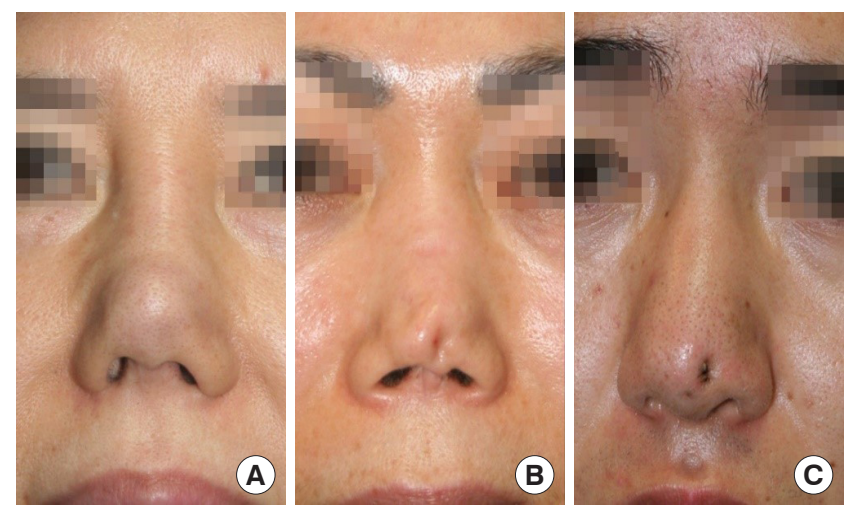

Fig. 11. An injured nasal envelope due to chronic inflammation. (A) Contracture with silicone implant. (B) Extrusion of silicone implant. (C) Deformity with gore-tex implant.

cal results and outcome is difficult to predict before the operation because every tip plasty affects the nasal base on the final result afterwards.

The topographic anatomy of the nasal base is illustrated as (Fig. 14) [19], including columellar base, central columellar pillar, infralobule (infralobular triangle), soft triangle (facet), lateral wall of ala, alar base, and nostril sill. Alar rim breakpoint (nostril break point) is caused by central sweeping of lateral crura away from alar rim. This point is a junction of tip lobule (lateral wall of ala in subunit) and alar base in lateral view. Alar base is composed of subcutaneous tissue and muscles. The soft triangle (facet) is the surface expression of domal notch in the nose. This area reflects the entire middle crus, beginning at the columellar breakpoint and continuing into the medial half of the lateral crus. The boundary and shape in this area are obscure due to thick skin in Asian and no cartilage within the facet. A scar contracture on this area by surgical manipulation might cause alar notching or retraction. The nostril sill serves

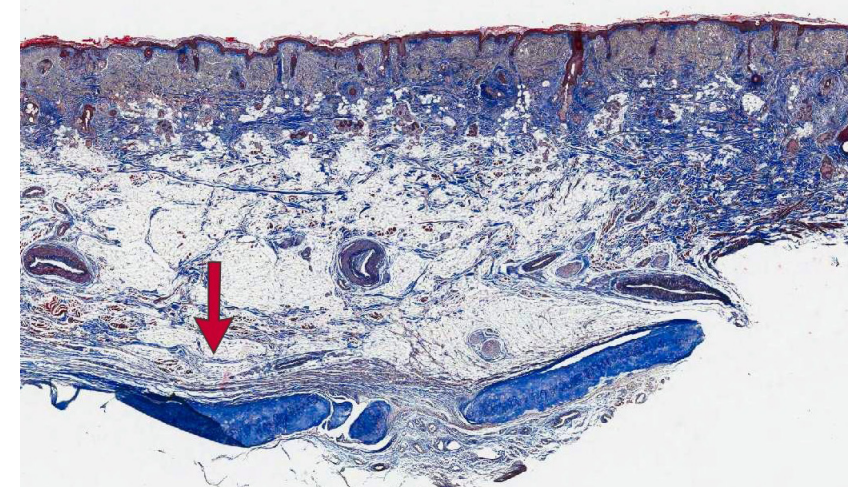

Fig. 12. Periosteal component and perichondral component are fused and form a hard-longitudinal fibrous sheath (red arrow) (Masson's Trichrome stain, $\times 20$ ).
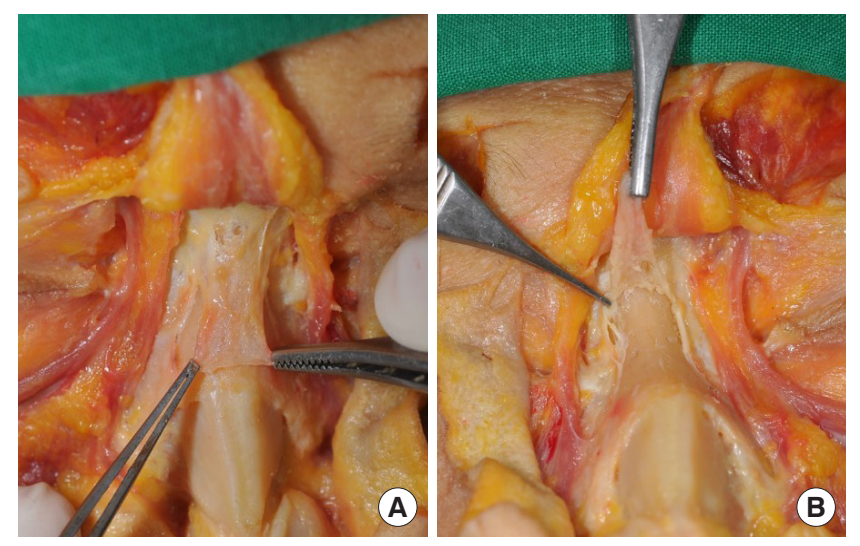

Fig. 13. (A, B) Periosteum of the nose.

as a transverse bridge from the columellar base to the alar lobule and as a longitudinal bridge from the nasal vestibule to the upper lip [20].

The pyriform ligament first named by Rohrich et al. [21] in 2008 is a fascial support peripheral to alar cartilage. It had vari- 


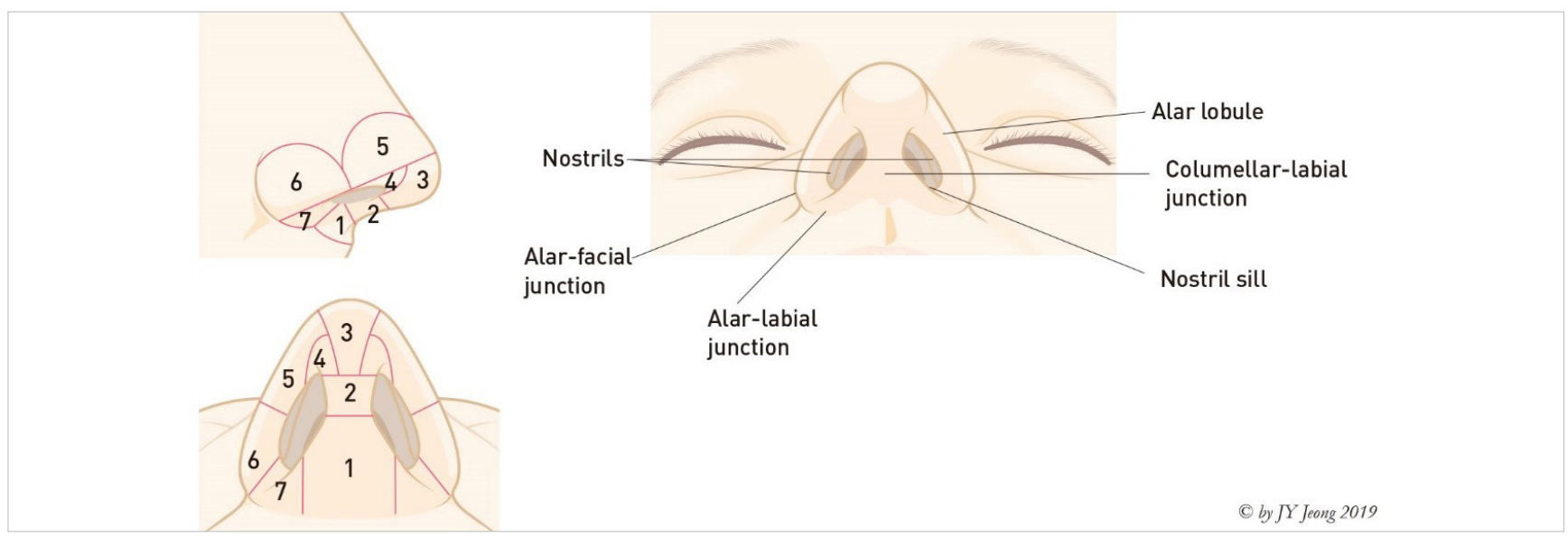

Fig. 14. Nasal base anatomy. (1) Columellar base, (2) central columellar pillar, (3) infralobular triangle, (4) soft triangle (facet), (5) lateral wall, (6) alar base, (7) nostril sill [19]. Reprinted from Jeong JY [1].

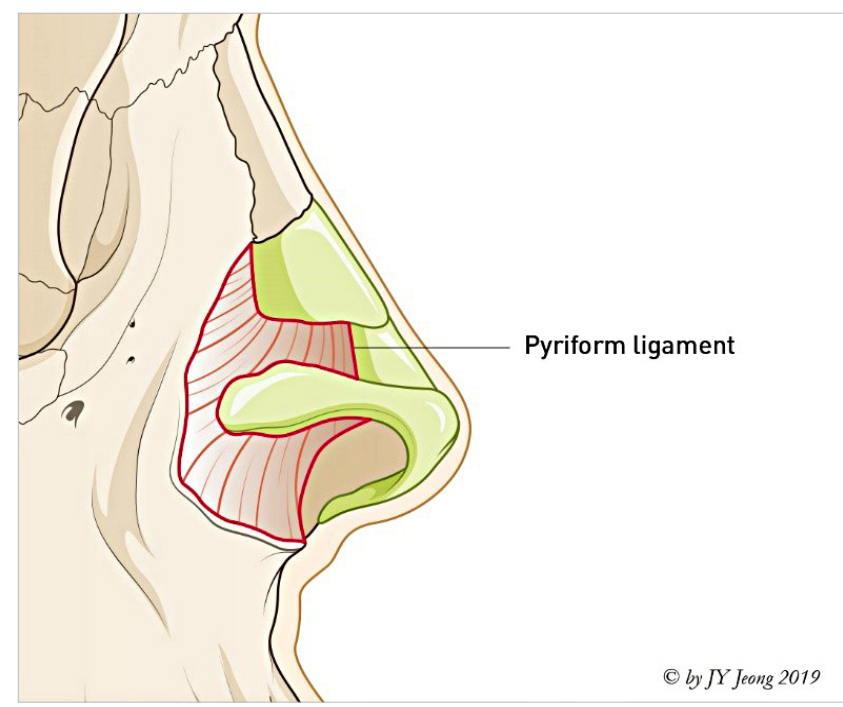

Fig. 15. Pyriform ligament (red line area). Reprinted from Jeong JY [1]

ous different names such as the lateral sesamoid complex ligament, lateral crural complex, nasal hinge and etc. Pyriform ligament can be understood as a wide fascial network system from nasal bone to anterior nasal spine. A condensation of pyriform ligament attached along the pyriform aperture is similar with the one in the orbit. In short, a pattern of pyriform ligament supporting alar cartilage is similar to the pattern of orbicularis oculi retaining ligament attaching to the orbital rim. It is connected to periosteum of maxilla in a fascial network (Fig. 15).

There is a distinct fibrous structure, "tela subcutanea cutis" described by Daniel et al. [20] laterally, without any muscular or cartilaginous component that forms alar side wall and nostril sill in the lower nasal base (Fig. 16). It is obvious that structural integrity of the alar side wall and nostril sill is well maintained without any support of underlying cartilages or bones. This structure is distinct soft tissue independent from cartilages and

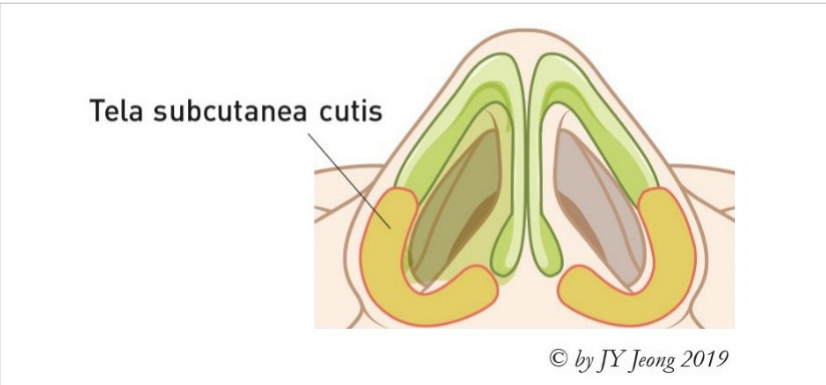

Fig. 16. Laterally, there is a distinct fibrous structure without any muscular or cartilaginous component that forms alar side wall and nostril sill in the lower nasal base. This specialized form is named by Goss and confirmed by Daniel [20]. It is obvious that structural integrity of the alar side wall and nostril sill is well maintained without any support of underlying cartilages or bones. This structure is distinct soft tissue independent of cartilages and bones. They are connected with muscles in base area. Reprinted from Jeong JY [1].

bones. They are connected with muscles in basal area.

\section{MUSCULAR SYSTEM}

Nasal muscles control facial animation and nasal respiration, during aerobic activity. Nasal muscles can be divided into four groups. All of them are innervated by temporal, zygomatic and buccal branch of facial nerve. The superficial nasal muscles are connected by their aponeurosis together, thus distributing their forces each other. There are numerous nomenclatures about nasal muscles, more detailed investigation is necessary since there are another intrinsic functional muscles beside listed nasal muscles [22,23]. This article quotes and follows descriptions by Letourneau and Daniel (Fig. 17) [22].

\section{Elevator muscles}

They shorten nasal length and dilate nostril. Procerus muscle: 

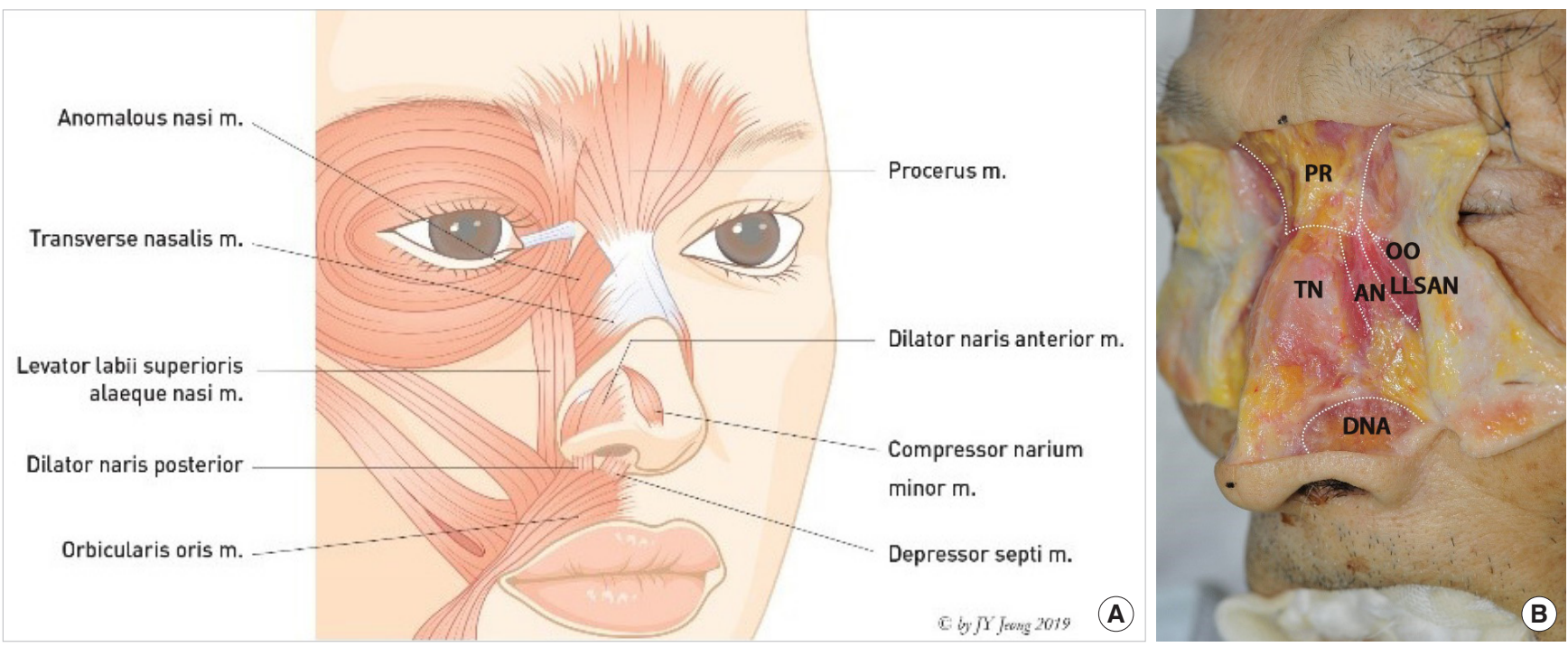

Fig. 17. (A) Illustration of nasal muscles. (B) Cadaver indicating nasal muscles. PR, procerus; TN, transverse nasalis; AN, anomalous nasi; LLSAN, levator labii superioris alaeque nasi; OO, orbicularis oculi; DNA, dilator naris anterior. Reprinted from Jeong JY [1].

originates from the periosteum of the nasal bones and the aponeurosis of the transverse nasalis before inserting into the glabellar skin. Levator labii superioris alaeque nasi muscle: originates from the periosteum of the frontal process of the maxilla medial to the orbicularis oris, and inserts at muscle and skin of nasolabial fold, nasal alae and upper lip [20]. Anomalous nasi muscle: originates from the frontal process of the maxilla. The origin of the anomalous nasi muscle was located medial to the middle part of the levator labii superioris alaeque nasal muscle. It ascended superomedially to blend with the procerus below the level of the medial palpebral ligament [24].

\section{Depressor muscles}

They lengthen nasal length and dilate nostril. Dilator naris posterior muscle (alar portion of the nasalis muscle): the main portion of the dilator naris posterior originates from the periosteum of the maxilla above the canine tooth and inserts into the alar base. Depressor septi nasi muscle: originates from the periosteum of the maxilla above the canine tooth and inserts onto the footplates of the medial crura with attaching tightly to the anterior nasal spine and mucosa, perichondrium and membranous septum $[25,26]$.

\section{Compressor muscles}

Transverse nasalis muscle (transverse portion of the nasalis muscle): originates from the periosteum of the maxilla above and lateral to the incisor fossa. It interdigitates on the nasal dorsum with its counterpart from the opposite side and the procerus muscle to form a sling [22,23,27-29]. Compressor narium minor muscle: originates from the tail of the lateral crura and

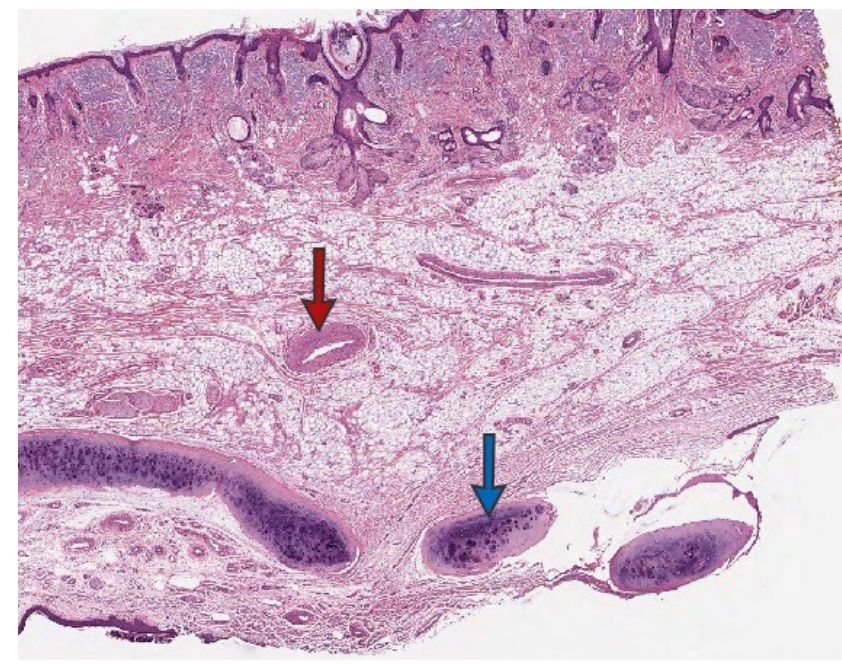

Fig. 18. A major circulatory system runs within or above nasal superficial musculo-aponeurotic system in the cross section of the nose (H\&E stain, $\times 40$ ). Lateral nasal artery (red arrow), sesamoid cartilage (blue arrow). Reprinted from Jeong JY. J Korean Soc Aesthetic Plast Surg 2010;16:125-38 [30].

the accessory cartilages before inserting into the deep dermal surface of the alar groove.

\section{Minor dilator muscle}

Dilator naris anterior muscle: originates from the surface of the lateral crus and inserts into the nostril rim.

\section{CIRCULATORY SYSTEM}

It is safe to dissect under nasal SMAS during the operation because nasal circulatory system runs within or above the nasal 


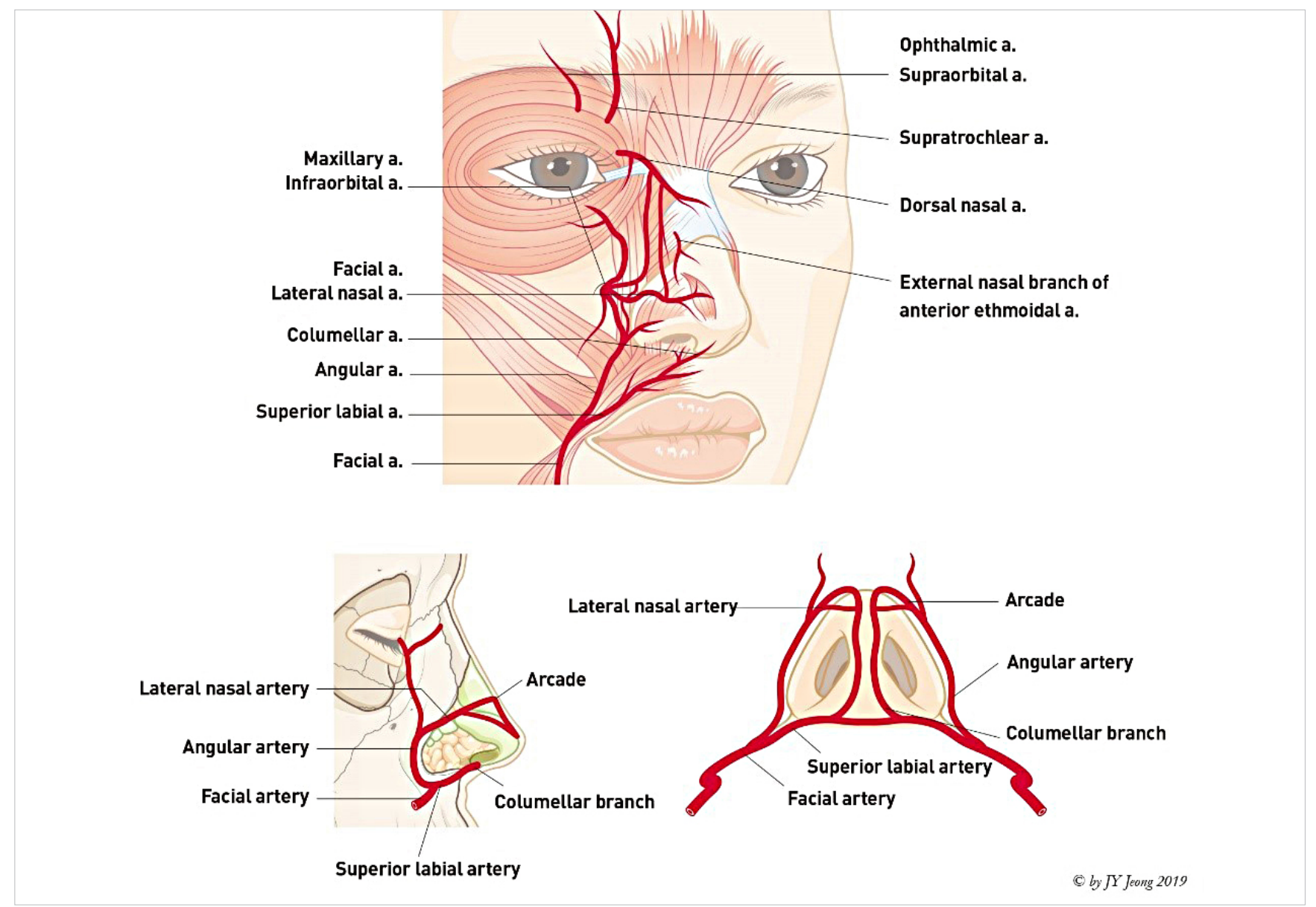

Fig. 19. Arteries of external nose [31]. Reprinted from Jeong JY [1].

SMAS (Fig. 18) [30]. The superficial blood supply of the nose is originated from ophthalmic artery, a branch of internal carotid artery, facial artery, a branch of external carotid artery and internal maxillary artery (Fig. 19) [31]. These arteries form vascular arcades in various patterns as it reaches the nasal periphery. A circulatory problem rarely happens even though several branches are injured since there is overlapped territory. Blood is supplied as dual perfusion or split perfusion at the center of the nose from bilateral branches with unilateral dominance [32]. It is related to facial asymmetry, which coincide with bone or soft tissue dominance. The representative vascular branches will be introduced in this section because they are different depending on the authors or anatomic variants.

\section{Ophthalmic artery}

\section{Dorsal nasal artery}

A dorsal nasal artery descends laterally from above medial canthal tendon through orbital septum and forms axial arterial network supplying abundant blood to nasal dorsal flap after meeting with supratrochlear and infra-orbital artery (Fig. 19).

\section{External nasal branch of ethmoidal artery}

External nasal branch of ethmoidal artery and lateral branch of angular artery are responsible for blood supply mainly nasal tip (Fig. 19) [33].

\section{Branches of facial artery}

\section{Angular artery}

It passes between alae and cheek, and runs into levator labii superioris alaeque nasi muscle. A lateral nasal artery is branched from the angular artery and mainly supplies the lateral aspect of nasal dorsum and tip [34]. It has 7-12 small branches while making anastomosis with opposing vessels at the nasal dorsum. After penetrating muscles, these branches form subdermal plexus at the nostril and cheek [35-37].

\section{Columellar artery}

It is a branch of superior labial artery ascending on the medial crura of alar cartilage within the columella. Anatomic variants such as absence of unilateral or bilateral branches are frequently observed [38]. 


\section{Branches of internal maxillary artery \\ External nasal branch of infraorbital artery}

When exiting the infraorbital foramen, an infraorbital artery has many branches running lateral aspect of nose.

\section{Venous drainages}

An external nasal vein usually accompanies with the matched artery. It mainly drains into the cavernous sinus through ways of facial vein, pterygoid plexus and ophthalmic vein. In addition, it forms the anastomosis with lateral branches of angular artery.

\section{Kiesselbach's plexus}

The Kiesselbach's plexus refers to gathering of terminal branches of vessels at anterior portion nasal septum. There are septal branches of anterior ethmoidal artery, sphenopalatine artery,

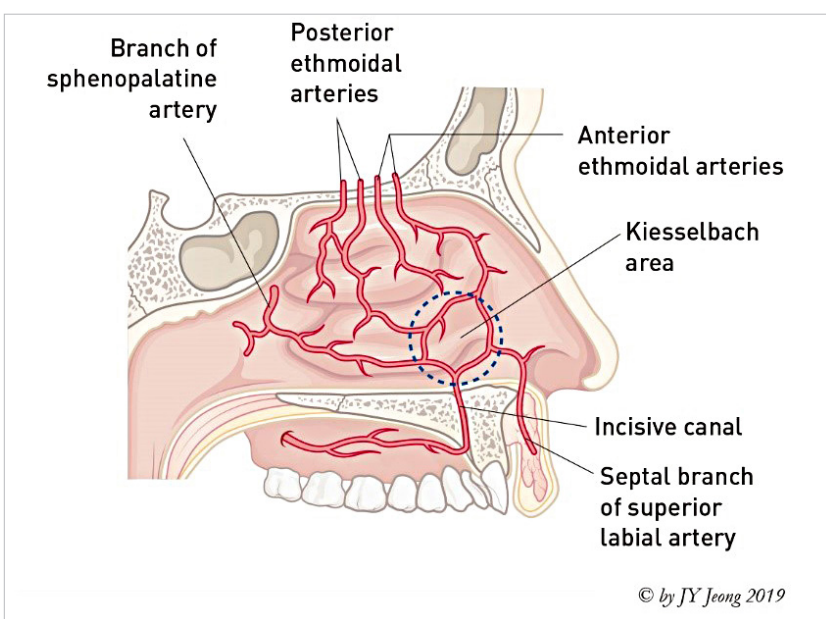

Fig. 20. The Kiesselbach's plexus refers to gathering of terminal branches of vessels at anterior portion nasal septum. There are septal branches of anterior ethmoidal artery, sphenopalatine artery, greater palatine artery and the anterior portion of the septum. Reprinted from Jeong JY [1]. greater palatine artery and the anterior portion of the septum. It is also known as the Little's area and is the most common cause of bleeding at septal anterior portion, which accounts for $90 \%$ of total cause of nasal bleeding (Fig. 20). It is frequent among toddlers and young patients. Although causes are various, the main cause of nasal bleeding at anterior portion is iatrogenic or traumatic including frequent picking or blowing nose. A nasal bleeding due to trauma mainly originates from mucosal injury whether it is related to nasal bone fracture or not [39].

\section{NERVOUS SYSTEM}

\section{External sensory nervous system}

The external sensory nerves of the nose originate from the first branch (ophthalmic nerve) and the second branch (maxillary nerve) of trigeminal nerve (Fig. 21).

\section{Ophthalmic nerve}

The supra-trochlear nerve and infra-trochlear nerve which are branches of ophthalmic nerve are innervated by the sensory

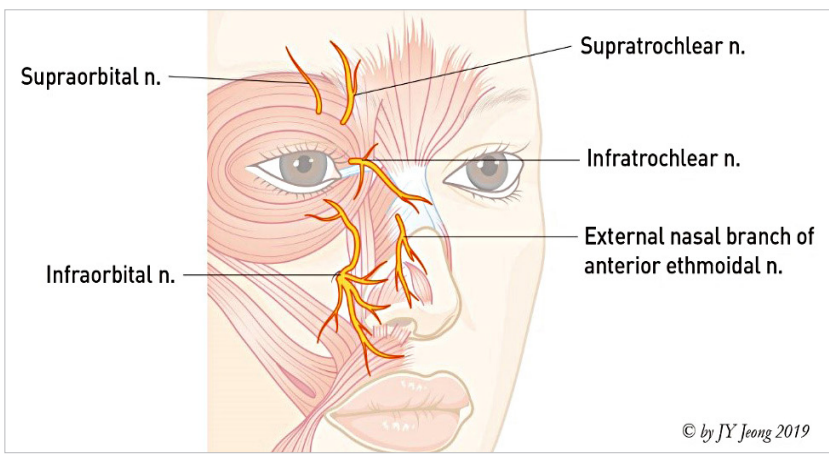

Fig. 21. External sensory nerves [31]. Reprinted from Jeong JY [1].

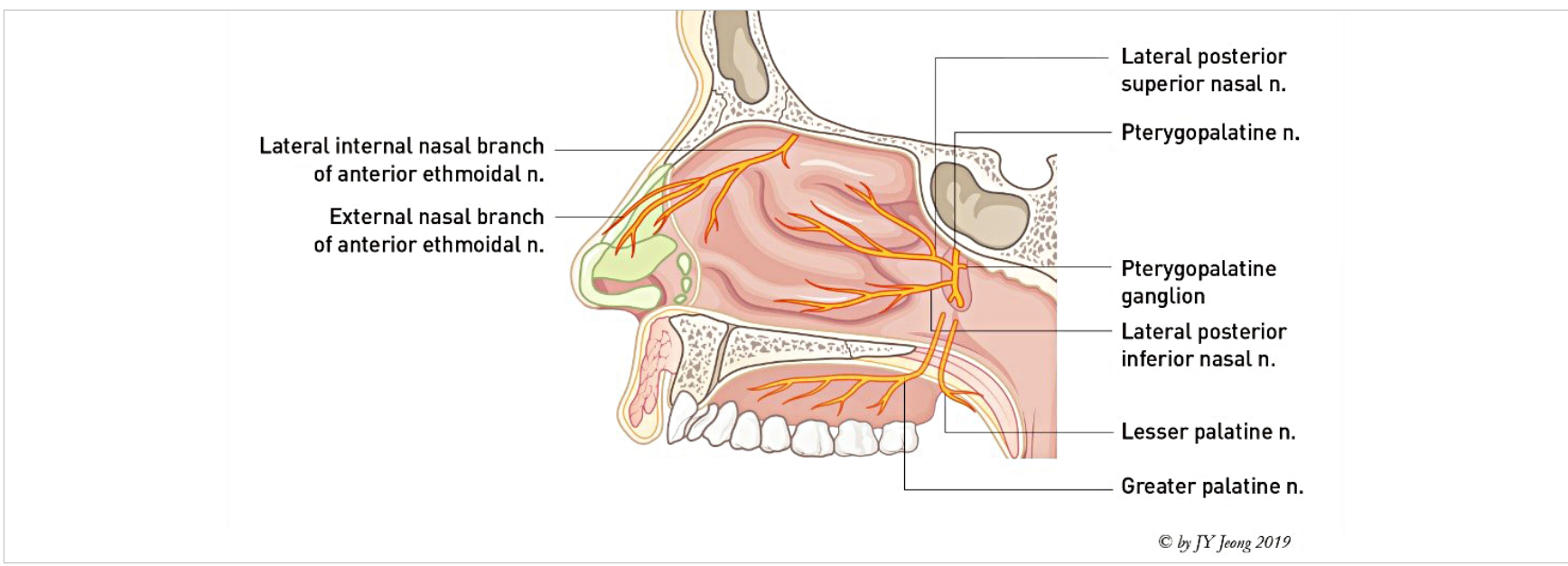

Fig. 22. Internal nervous system of lateral nasal wall. Reprinted from Jeong JY [1]. 


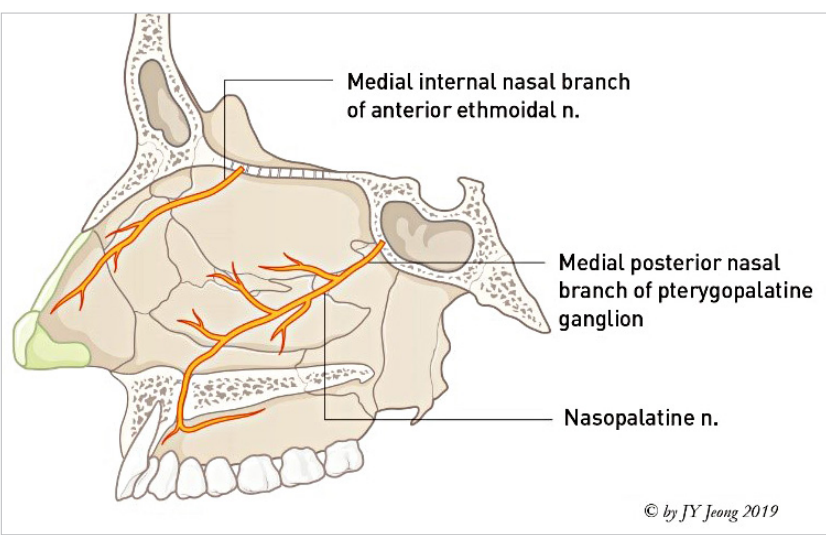

Fig. 23. Internal nervous system of septal area. Reprinted from Jeong JY [1].

nasal root and some part of nasal lateral wall.

The external nasal branch of anterior ethmoidal nerve is the most important sensory nerve inne rvating the nasal tip. It runs from nasal dorsum to nasal tip after sprouting out between nasal bone and upper lateral cartilage. It is common to observe patients having transient sensory discomfort due to nerve injury or edema during early phase after rhinoplasty [40,41]. A nerve injury is especially more frequent after hump reduction or wide subperiosteal dissection, which usually recovers spontaneously within several months after surgery. It is necessary to gain full consensus about any symptoms related to nerve, although it is rare to have complete sensory loss, patients may suffer from temporary sensory loss, discomfort, paresthesia, neuroma and so on [42].

\section{Maxillary nerve}

The infraorbital nerve, a branch of maxillary nerve, innervates the sensory of lateral wall of lower nose, columella, nasal vestibule and so on.

\section{Internal nervous system}

The nerves branched from pterygo-palatine ganglion located at posterior of middle turbinate are mainly innervating the nasal interior. The internal branch of anterior ethmoidal nerve innervates the anterior portion of nasal lateral wall and septum. The nasopalatine nerve branched from the pterygo-palatine ganglion is the main sensory innervation for the septum (Figs. 22, 23).

\section{NOTES}

\section{Conflict of interest}

No potential conflict of interest relevant to this article was reported.

\section{Ethical approval}

This study was performed in accordance with the principles of the Declaration of Helsinki. Written informed consent was obtained.

\section{Patient consent}

The patients provided written informed consent for the publication and the use of their images.

\section{ORCID}

Taek Kyun Kim https://orcid.org/0000-0002-3213-9803

Jae Yong Jeong https://orcid.org/0000-0001-5654-4443

\section{REFERENCES}

1. Jeong JY, Kim TK. Rebuilding nose: rhinoplasty for Asians. Uijeongbu: Medic Medicine; 2018.

2. Kim DA, Jeong JY, Oh SH. Bulbous tip correction focusing on skin soft tissue envelope in Asian rhinoplasty. Arch Aesthetic Plast Surg 2014;20:140-7.

3. Wu WT. The oriental nose: an anatomical basis for surgery. Ann Acad Med Singapore 1992;21:176-89.

4. Ha RY, Nojima K, Adams WP Jr, Brown SA. Analysis of facial skin thickness: defining the relative thickness index. Plast Reconstr Surg 2005;115:1769-73.

5. Kosins AM, Obagi ZE. Managing the difficult soft tissue envelope in facial and rhinoplasty surgery. Aesthet Surg J 2017;37: 143-57.

6. Hafezi F, Naghibzadeh B, Nouhi A. Management of the thickskinned nose: a more effective approach. Ann Otol Rhinol Laryngol 2006;115:444-9.

7. Burget GC. Aesthetic reconstruction of the tip of the nose. Dermatol Surg 1995;21:419-29.

8. Burget GC, Menick FJ. The subunit principle in nasal reconstruction. Plast Reconstr Surg 1985;76:239-47.

9. Burget GC, Menick FJ. Aesthetic reconstruction of the nose. St. Louis: Mosby; 1994.

10. Mathes SJ. Plastic surgery. 2nd ed. Philadelphia: Elsevier; 2005.

11. Daniel RK, Palhazi P. Rhinoplasty: an anatomical and clinical atlas. Cham: Springer International Publishing; 2018.

12. Coskun N, Yavuz A, Dikici MB, Sindel T, Islamoglu K, Sindel M. Three-dimensional measurements of the nasal interdomal fat pad. Aesthetic Plast Surg 2008;32:262-5.

13. Ghassemi A, Prescher A, Riediger D, Axer H. Anatomy of the SMAS revisited. Aesthetic Plast Surg 2003;27:258-64.

14. Saban Y, Andretto Amodeo C, Hammou JC, Polselli R. An anatomical study of the nasal superficial musculoaponeurotic system: surgical applications in rhinoplasty. Arch Facial Plast 
Surg 2008;10:109-15.

15. Jeong JY. Advanced rhinoplasty anatomy: updates of surgical concept and application. Presented at the Rhinoplasty Symposium Seoul 2010; Jun 19, 2010.

16. Oneal RM, Beil RJ Jr, Izenberg PH, Schlesinger J. Surgical anatomy of the nose. Oper Tech Plast Reconstr Surg 2000;7:158-67.

17. Squier CA, Ghoneim S, Kremenak CR. Ultrastructure of the periosteum from membrane bone. J Anat 1990;171:233-9.

18. Tsai FC, Liao CK, Fong TH, Lin JY, Wu ST. Analysis of nasal periosteum and nasofrontal suture with clinical implications for dorsal nasal augmentation. Plast Reconstr Surg 2010;126: 1037-47.

19. Daniel RK. Mastering rhinoplasty. 2nd ed. New York: SpringerVerlag; 2010.

20. Daniel RK, Glasz T, Molnar G, Palhazi P, Saban Y, Journel B. The lower nasal base: an anatomical study. Aesthet Surg J 2013; 33:222-32.

21. Rohrich RJ, Hoxworth RE, Thornton JF, Pessa JE. The pyriform ligament. Plast Reconstr Surg 2008;121:277-81.

22. Letourneau A, Daniel RK. The superficial musculoaponeurotic system of the nose. Plast Reconstr Surg 1988;82:48-57.

23. Lam SM, Williams EF 3rd. Anatomic considerations in aesthetic rhinoplasty. Facial Plast Surg 2002;18:209-14.

24. Lee JY, Hur MS. An anatomical description of the anomalous nasi muscle. Korean J Phys Anthropol 2017;30:109-12.

25. Jeong JY, Oh SH, Lee SR, Kang NH, Kim DW. Muscular system of depressor septi nasi: anatomical study and clinical application. J Korean Soc Aesthetic Plast Surg 2009;15:49-54.

26. Oh SH, Choi S, Kim DW, Jeong JY. Intranasal approach for manipulating the depressor septi nasi. J Craniofac Surg 2012; 23:367-9.

27. Jeong J, Terence G, Kim J. Understanding the anatomy of the transverse nasalis aponeurotic fibers and its importance in Asian rhinoplasty. Ann Plast Surg 2018;81:516-22.

28. Jeong JY, Yoo YA, Kang NH, Oh SH. Expansion procedures of the nasal envelope in short nose deformity: release of the transverse nasalis sling and division of muscle confluence in nasal Hinge Area. J Korean Soc Aesthetic Plast Surg 2010;16:78-84.

29. Daniel RK, Letourneau A. Rhinoplasty: nasal anatomy. Ann
Plast Surg 1988;20:5-13.

30. Jeong JY. Tripod framework rebuilding in Asian nose: tip plasty using alar advancement technique. J Korean Soc Aesthetic Plast Surg 2010;16:125-38.

31. Oneal RM, Beil RJ Jr, Schlesinger J. Surgical anatomy of the nose. Clin Plast Surg 1996;23:195-222.

32. Banks ND, Hui-Chou HG, Tripathi S, Collins BJ, Stanwix MG, Nam AJ, et al. An anatomical study of external carotid artery vascular territories in face and midface flaps for transplantation. Plast Reconstr Surg 2009;123:1677-87.

33. Toriumi DM, Mueller RA, Grosch T, Bhattacharyya TK, Larrabee WF Jr. Vascular anatomy of the nose and the external rhinoplasty approach. Arch Otolaryngol Head Neck Surg 1996; 122:24-34

34. Nakajima H, Imanishi N, Aiso S. Facial artery in the upper lip and nose: anatomy and a clinical application. Plast Reconstr Surg 2002;109:855-61.

35. Koh KS, Kim HJ, Oh CS, Chung IH. Branching patterns and symmetry of the course of the facial artery in Koreans. Int J Oral Maxillofac Surg 2003;32:414-8.

36. Loukas M, Hullett J, Louis RG Jr, Kapos T, Knight J, Nagy R, et al. A detailed observation of variations of the facial artery, with emphasis on the superior labial artery. Surg Radiol Anat 2006; 28:316-24.

37. Niranjan NS. An anatomical study of the facial artery. Ann Plast Surg 1988;21:14-22.

38. Rohrich RJ, Muzaffar AR, Gunter JP. Nasal tip blood supply: confirming the safety of the transcolumellar incision in rhinoplasty. Plast Reconstr Surg 2000;106:1640-1.

39. Koh E, Frazzini VI, Kagetsu NJ. Epistaxis: vascular anatomy, origins, and endovascular treatment. AJR Am J Roentgenol 2000;174:845-51.

40. Bafaqeeh SA, al-Qattan MM. Alterations in nasal sensibility following open rhinoplasty. Br J Plast Surg 1998;51:508-10.

41. Han SK, Shin YW, Kim WK. Anatomy of the external nasal nerve. Plast Reconstr Surg 2004;114:1055-9.

42. Thompson AC. Nasal tip numbness following rhinoplasty. Clin Otolaryngol Allied Sci 1987;12:143-4. 